\title{
Personas-Driven Design for Mental Health Therapeutic Applications
}

\author{
K. R. H. Rodrigues*, F. E. Garcia ${ }^{\dagger}$, L. F. Bocanegra ${ }^{\ddagger}$, V. P. Gonçalves ${ }^{\S}$, V. G. Carvalho ${ }^{\Uparrow}$, V. P. A. Neris $\|$ \\ Universidade Federal de São Carlos (UFSCar) \\ São Carlos, São Paulo, Brazil \\ Email: *kamila_rodrigues@dc.ufscar.br, ${ }^{\dagger}$ franco.garcia@dc.ufscar.br, ${ }^{\dagger}$ lucasfernandobocanegra@gmail.com, \\ §vpg@icmc.usp.com, 『vgdcarvalho@gmail.com, ||
}

\begin{abstract}
Digital applications for mental therapy can support the rehabilitation treatments and help patients to motivate themselves, understand and persist in therapeutic practices. Although the importance and use of these software systems continue to increase, the literature does not specify a consolidated methodology to design such applications. This paper describes a participatory process to enrich Personas, aiming to characterize the intended audience of therapeutic applications in the context of mental health. Moreover, the paper presents how the information obtained in the process can aid on therapeutic games design aiming to support the rehabilitation of chemical dependent and depressive patients.
\end{abstract}

Index Terms-Personas; Therapeutic Software Systems; Participatory Design; Organizational Semiotics; Health.

\section{INTRODUCTION}

D IGITAL therapeutic applications — in special, therapeutic games - are tools to support healthcare professionals to treat their patients. These applications may help patients in different ways, such as aiding on their rehabilitation, helping them to understand their condition and the treatment procedures, or even motivating themselves to persist on ongoing treatments. Healthcare professionals may use therapeutic applications to help the patients express their feelings, relax, or improve their own abilities and personal relationships [1].

The Literature describes different medical domains for therapeutic applications, ranging from physical conditions, such as motor disorders [2] and strokes [3], [4], to mental ones [5], [6].

One important aspect to creating therapeutic application is the combination of efforts from as many stakeholders as possible. Cheung [1] affirms that the involvement of different stakeholders - such as patient, family, and healthcare professionals - results in more effective treatments, often with better results.

From a software development perspective, the involvement of stakeholders is crucial - medical care involves human lives. As the name suggests, therapeutic applications have a therapeutic purpose; therefore, one must have special attention to requirements analysis. Requirements vary according to medical procedures. They may encompass, for instance, the clinical profile of the patients, therapeutic techniques and procedures for the treatment, and the expected effects that the application will have on the user.
Depending on the condition and procedures, it might be difficult to generalize personal characteristics of each patient. Therefore, therapeutic applications should be highly flexible. This is important both to healthcare professionals and to patients. On the one hand, the professionals might want - or need - to customize the system to the treatment goals. Such changes might include modifying the user interface, adding new interaction mechanisms or new functionalities. On the other hand, patients interaction needs may vary; thus, a single non-modifiable interaction scheme may not suit everyone.

Due to the required flexibility and understanding of users and treatment context, requirements analysis for therapeutic applications must be granular. As software developers are usually not healthcare professionals, one key requirement for the analysis is to provide the required information in an accessible way to designers. To achieve this, one possibility is to explore Personas [7], [8]. Cooper [7] defines Personas as concrete and realistic representations - based on real or fictitious details - to create faithful representations of users of a system.

Personas allow designers to document, organize and represent the diversity of possible users of a system [9]. Designers might include demographic, economic, and behavioral data onto a Persona to map relevant data into a detailed representation of users [10], [11]. They may describe physical and mental characteristics of users, their histories, and daily and professional activities. Thus, for requirements analysis, designers may use Personas to richly represent users of the resulting computational system. The technique has been used for designing projects with millions of users, such as Filgueiras et al. [12], who used Personas to create user models for São Paulo's e-government services.

However, as Cheung [1] noted, for more effective therapeutic results, one must include different stakeholders. Therefore, therapeutic applications could benefit from participatory Personas creation: when different stakeholders contribute to create a product, it increases the chances of achieving better quality. Particularly, one might expect a more suitable product, which better corresponds to the characteristics and needs of end-users.

Moreover, due to the dynamic behavior of medical treatments, designers must consider and predict potential use cases, such as the evolution of clinical profiles, or even the use of the application under other environments or devices. To 
allow designers to address these issues, one needs a sociotechnical vision, encompassing an ample comprehension of the problem domain and of the use context. For this, one may consider exploring methods and artifacts of Organizational Semiotics' [13], [14].

In this paper, we discuss the creation of two Personasdriven, flexible digital therapeutic games for mental health: one intended to patients with depression, another to chemical dependency. This papers extends our previous work [15], published in the XIII Brazilian Symposium on Human Factors in Computer Systems.

Here we discuss the creation, enrichment, and evaluation of Personas with healthcare professionals, and how we used the Personas to design the games. Our work explored Organizational Semiotics methods and artifacts (including the Evaluation Frame [16], and the Stakeholders Analysis Chart [17]) using participatory techniques alongside Hospital Espírita de Marília's (HEM) healthcare professionals.

In our requirements analysis, we collaborated with HEM psychiatrists, psychologists, nurses, occupational therapists, and social workers to gather data to define Personas. In our analysis, we have considered patients' clinical profiles, life histories, habits and motivations, and the professionals' procedures and techniques to treat them. HEM's professionals took part in participatory workshops, aiding us to create, enrich, and validate of Personas representing patients with either depression, or chemical dependency. The process resulted in six enriched Personas: three representing depressive patients, three representing chemical dependents.

We discuss how we used the six Personas to guide the design process of the therapeutic games. We present a Design Rationale (DR) to show how Personas aided on informed decisions to design the games. We use a low-fidelity prototype to illustrate how Personas guided design decisions, and how they affected the gameplay and the user interface of the games.

This paper is organized as follows: Section II comments the theoretical frameworks we have followed in our work. Section III describes our Personas Enrichment Process: an approach to created enriched Personas aimed to support mental health therapeutic applications. Section IV illustrates the creation of six Personas using the defined approach. Section V comments how we used the Personas to design prototypes to the therapeutic games. Section VI presents conclusions and future work.

\section{THEORETICAL FRAMEWORKS}

\section{A. Personas and Cooper's Personas Process}

Cooper [7] created the Personas technique in 1999. Like Cooper, Pruitt and Adlin [18] define Personas as fictitious, specific, and concrete representations of the intended audience. The technique congregates data from different sources - such as demographic, biographical, or even created - onto a character that tries to represent, as accurately as possible, the reality of end-users. Thus, to achieve the required verisimilitude, Personas are rich in details. They may have any information required to model the reality and the problem domain. For instance, a Persona may have the following information: name; physical, mental, and biological characteristics; age; a life story; and a visual representation.

Personas have a life-cycle. As Cooper [7] had first defined it, we will call, on this paper, his original process the Cooper's Personas Process. The life-cycle of Cooper's Personas Process has the following sequential phases [7], [18]: (1) familiar planning, (2) conception and gestation, (3) birth and maturation, (4) adulthood, and (5) retirement. Developers use the adult Personas; after the project, they retire the Personas, that is, they abandon them, as they have served their purpose. Designers might discard the Personas or may reuse existing them on future projects with the same intended audience.

1) Familiar Planning: In the first phase of a Persona's life-cycle, a team of designers should: (i) meet and create the Persona; (ii) research and identify problems which the application should address; (iii) gather the required data to address the problem; (iv) use the chosen problems and data as the raw building material for the Persona; and (v) define an action plan.

2) Conception and Gestation: In the second phase, designers process the gathered data. Their goal is to transform the data into relevant information to address the design problem. The resulting information serve as skeletons for Personas.

Designers may create several Personas at this phase. Regardless of the total number, they should evaluate each Persona, choose and prioritize the most important ones, and validate them afterwards.

3) Birth and Maturation: This phase marks the transition between the creation and use of a Persona. On it, designers send and present the Personas to the application's stakeholders. They first discuss with the main requester, then with other relevant stakeholders. The goal of the designers is to refine the Personas, to gradually improve and make them more realistic, that is closer to the real users they should represent.

4) Adulthood: At this phase, designers employ the Personas on the design process. Designers use the Personas to make choices regarding their solution, and to discuss how to address their needs into the product. Ideally, as each Persona was created to match and symbolize the problem, it should be a close representation of the application's real users' requirements.

5) Retirement: After the design process, designers evaluate the Personas' effectiveness as an aid to the process, and regarding the Persona's realizations. Provided the Personas were effective enough, the designers might reuse the Personas into future projects with the same intended audience - Cooper [7] names this reuse as reincarnation.

\section{B. Personas Applied to Healthcare Systems}

Mader et al. [19] suggests that Personas might be suitable to the design of therapeutic games: they used the technique to model users for their therapeutic game. Other works seem to corroborate with this suggestion. Orcas [20] is an example of Personas applied to the design of healthcare systems. Shared Healthcare Systems (SHS) asked Cooper Interaction Design to create an integrated computing system which would allow healthcare professionals to manage their patients, and administrators to manage payrolls and insurance processes. 
According to Achterkamp et al. [21], technological services supporting health lifestyles demonstrates short-term effects to the user. The results are increasing the interest of the research community regarding the use of such technologies. However, the authors note that long-term compliance to such services is slow. Additionally, they describe an ongoing research regarding automated goals definition and tailored feedback messages to improve the life quality of the user. They explored Personas to define which messages they should send for users with a determined profile. They based their Personas on behavioral science theories, and domains specialists categorized the Personas during a workshop. Their results suggest a reasonable correspondence of motivational messages based on eight Personas. However, the authors do not detail the process they used to create the Personas - this would be useful to help researchers creating new ones.

LeRouge et al. [22] describe an example of healthcare system designed with Personas following Cooper's Personas Process. LeRouge et al. [22] suggest that, to create an effective healthcare system, it is necessary to achieve personal connections levels to capture the essence regarding users groups and their respective problems. They say that one may explore user profiles and Personas to help the development team on visualizing and communicating with the users. These authors warn about the importance of the characteristics of the user profiles: they affirm that the users are consumers of healthcare technologies.

In the cited works, designers defined the Personas themselves, instead of end-users or domain specialists. This might compromise peculiarities and the context of use of the application, especially when one considers the healthcare domain. In this domain, part of the data might be unavailable or restricted to designers, due to practical or ethical reasons - such as patients profiles' empirical data [23].

As such, one might argue that Cooper's Personas Process might not be enough for a complex domain, such as healthcare. The dependency of the designers' domain expertise to create the Personas might compromise identifying design inner details, which may be crucial to design. As designers are (usually) not end-users of the system, they might miss the context of use. Thus, it is necessary to combine the knowledge — and needs - of different stakeholders into the Personas creation to bring them closer to the reality.

To address this, Wärnestål et al. [23] describe an alternative approach to create Personas. They tailored their approach to the healthcare domain, focusing on kids. They chose to focus kids due to a limited availability of technical resources which support daily living and improve the life of patients in intensive care, such as kids with cancer.

The Personas approach of Wärnestål et al. [23] explore workshop sessions with the kids regarding Salutogenesis, and interviews with their parents and healthcare professionals to obtain a complementary pathological perspective. Their approach uses comics to illustrate rescue scenarios and introduces the concept of Proxy Personas. They use comics in a colaboratory approach: kids and designers create the comics by storytelling.

Although the approach of Wärnestål et al. [23] to defining
Personas is similar to ours, their patients' profiles are different. Involving patients themselves in the profile creation and description would require a level of self-consciousness of which patients with mental or cognitive related diseases such as depression or chemical addiction - may not currently have. To address this, our work supports a participatory process to create, enrich, and evaluate Personas. We adopt a socio-technical vision, considering the users (patients) in their social, familiar, and therapeutic contexts, and include relevant stakeholders to the design process.

\section{Organization Semiotics, Stakeholders Analysis, and Eval- uation Frame}

Organizational Semiotics is a discipline with roots on semiotics applied to organizational processes. It studies the nature, characteristics, functions and effects of information and communication in organizational contexts. An organization is a social system in which people behave in an organized way, respecting a given set of norms. Norms are regularities of perception, behavior, beliefs, and values, expressed as habits, behavior patterns, and other cultural artifacts [13], [14].

As such, one may see any heterogeneous user population as an organization. According to Organizational Semiotics, one may see an organization as an information system in which agents use signs to perform intentional actions. Some organizational functions have high regularity, and have rules that can be clearly formalized. Computer-based systems may automatize repetitive rules. As such, software (technical system) is part of an information system, and presupposes formal systems. In this formal system, rules and formal procedures specify how to establish relations, and how to perform actions.

Furthermore, the formal system presupposes an informal system, in which the organizational culture, patterns and values reflect on beliefs, habits, and behavior patterns of each individual member. At this level, meanings are defined, intents are comprehended, and beliefs are made. Organizational Semiotics, therefore, provides a knowledge basis, and support collaboration and reflection between people with different backgrounds involved in the interaction design [24].

The Stakeholder Analysis Chart is an Organizational Semiotics' artifact that provides a comprehensive vision of the stakeholders in different contexts of interest [17]. A group may use the chart to discuss and identify parts that affect or undergo influence (directly or indirectly) in a situation to better understand the real situation of the problem and the solution's requirements [16].

The Evaluation Frame (which one should not confuse with the Valuation Frame) is another artifact. Designers use the framework to insert stakeholders' interests and problems to solve, and possible solutions resulting from discussions from all participants [16].

To develop a technical solution, one must know the formal and informal rules and norms of the corresponding context. To achieve this, we performed participatory workshops with the project team, stakeholders, and partners. Our goal was to discuss the meaning of the design solutions and the creation of the Personas. 


\section{Design Rationale: Documenting Design Decisions}

Rationale means reasons or intents involved in a set of thoughts or actions, or what motivated them. Techniques of Design Rationale allow one to manage the knowledge existent in a project, and to trace the history of analysis regarding an arbitrary artifact. Designers may use the techniques to document final design decisions. For every decision, they record their reasons, intents, analyzed alternatives, and factors which motivate the decision [25], [26].

It is important to record decisions because one may to wish understand the processes at a later time, or explore design on other projects. At any time, designers may find that a promising decision was a mistake; with the records, they may revisit considered alternatives to find a better approach.

As there are several available techniques to represent DR, we have adopted in this paper an adapted version of Questions, Options and Criteria (QOC) technique [27], due to its ease of drafting and understanding. QOC is based on the formulation of issues. Questions represent the major problems which designers should consider; besides, they make up the alternatives of the design space. Criteria are positive objectives, which serve as basis which allows designers to evaluate and choose the best among different options. Finally, options are the possibilities to answer design questions.

In this work, we used DR techniques to document decisions applied on different phases and times of the project. Some examples include: (1) choices of Personas to represent fictitious patients, (2) choices for the most adequate genre and game mechanics to address the treatment, (3) decisions of which stimuli to provide to the patients, and (4) choices regarding the art style, such as colors, traces, and sounds used to create the games' aesthetics.

\section{Personas Enrichment Process}

We believe that, to design for complex scenarios and domains, it is essential to have a multidisciplinary team and a broad vision of the problems, challenges, and opportunities. Thus, differently from Cooper's Personas Process, our proposed Personas Enrichment Process expects participation of the project's stakeholders. In a therapeutic application context, in particular, one should expect, at least, collaborations between healthcare and computer science professionals.

The stakeholders participating on the design (hereafter called design team) should strive to design the application together: the collaborative and participatory approach aims to increase the efficacy of the resulting system to the treatments' goals. Additionally, the design team should have a research approach characterized on theoretical frameworks for the design considering interpersonal, social and cultural perspectives [13], [28], [29].

The design team should aim to build an attractive system to the patients, which should, simultaneously, be efficient to the treatments goals. For instance, the healthcare goal might be helping the healthcare professional to improve a patient's compliance and continuity of the treatment. Furthermore, the therapeutic application should provide activities to promote social and cognitive improvements patients - without limiting their creativity or fun - and evaluation capabilities to the healthcare professionals [1], [30].

One possibility is to follow the recommendation of [31]: the design team should know classes of users who will interact with the system. In a therapeutic context, relevant information to know the patients' class might include: clinical profiles, age, and education. This kind of information helps the design team to predict the patients' learning difficulties and to determine appropriate limits to the user interface difficulty [32].

The incipient knowledge requires continuous contact from all the stakeholders: ideally, the design team should aim to perform a "build together, evaluate, formalize the lessons learned" cycle. Their first goal should be to clarify the problem. This includes knowing the stakeholders and detailing the end-user of the application. The following section presents four steps to out Personas Enrichment Process to characterize the intended audience for therapeutic applications.

\section{Steps of the Process}

The Personas Enrichment Process for therapeutic applications has four steps: (1) it starts with the identification of the stakeholders. (2) Afterwards, the design team identifies the end-users of the application, the problems to solve, and possible solutions. (3) With this information, the design team creates the Personas. (4) Finally, the design team presents and validates the Personas with the stakeholders. Fig. 1 illustrates the steps of the process.

1) Identification of the Stakeholders: The first step is to identify and define the stakeholders interested on the development of the therapeutic application. Organizational Semiotics describes Stakeholder Analysis, an artifact to help the design team on understanding the real situation of the problem and the requirements for the solution. To use it, the design team discusses and identifies the parts that influence (or are influenced by) the solution, either directly or indirectly.

Fig. 2 illustrates the Stakeholder Analysis Chart [33]. The design team used it to support the Stakeholder Analysis: the chart represents the stakeholders of the application. The chart is layered: each layer represents different concerns and responsibilities. The design team adds, on each layer, the characters involved in the problem and on its solution [14], [33].

It is possible to use the Stakeholder Analysis Chart participatively. One approach is to combine the knowledge of the computer science professionals and early participating stakeholders to identify and classify as many stakeholders as possible. For therapeutic applications, this might include, initially, computer science professionals, designers, researchers, and healthcare professionals. Depending on the problem complexity and characteristics, one may wish to include healthcare institutions administrators, government representatives, and even family and friends of the patients to the participatory practices. The design team may invite and incorporate important stakeholders to aid on future steps.

2) Characterizing the Users: Participatory Description of Users, Problems, and Possible Solutions: On the second step, the design team's goal is to identify end-users of the system 


\section{Personas Enrichment Process}

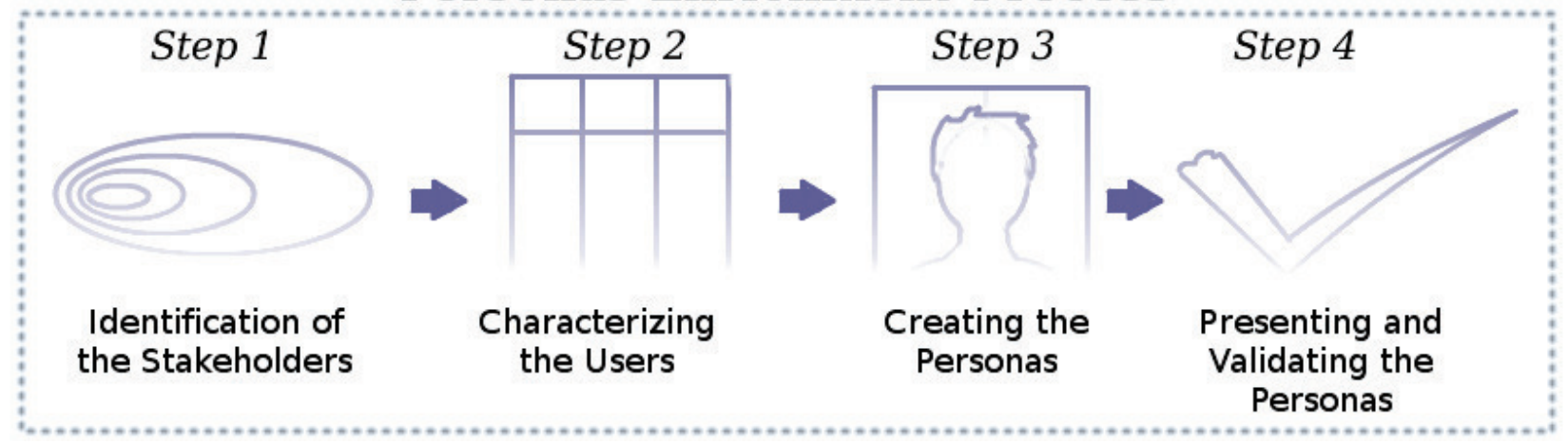

Fig. 1. Steps of the Personas Enrichment Process for the design of therapeutic applications.

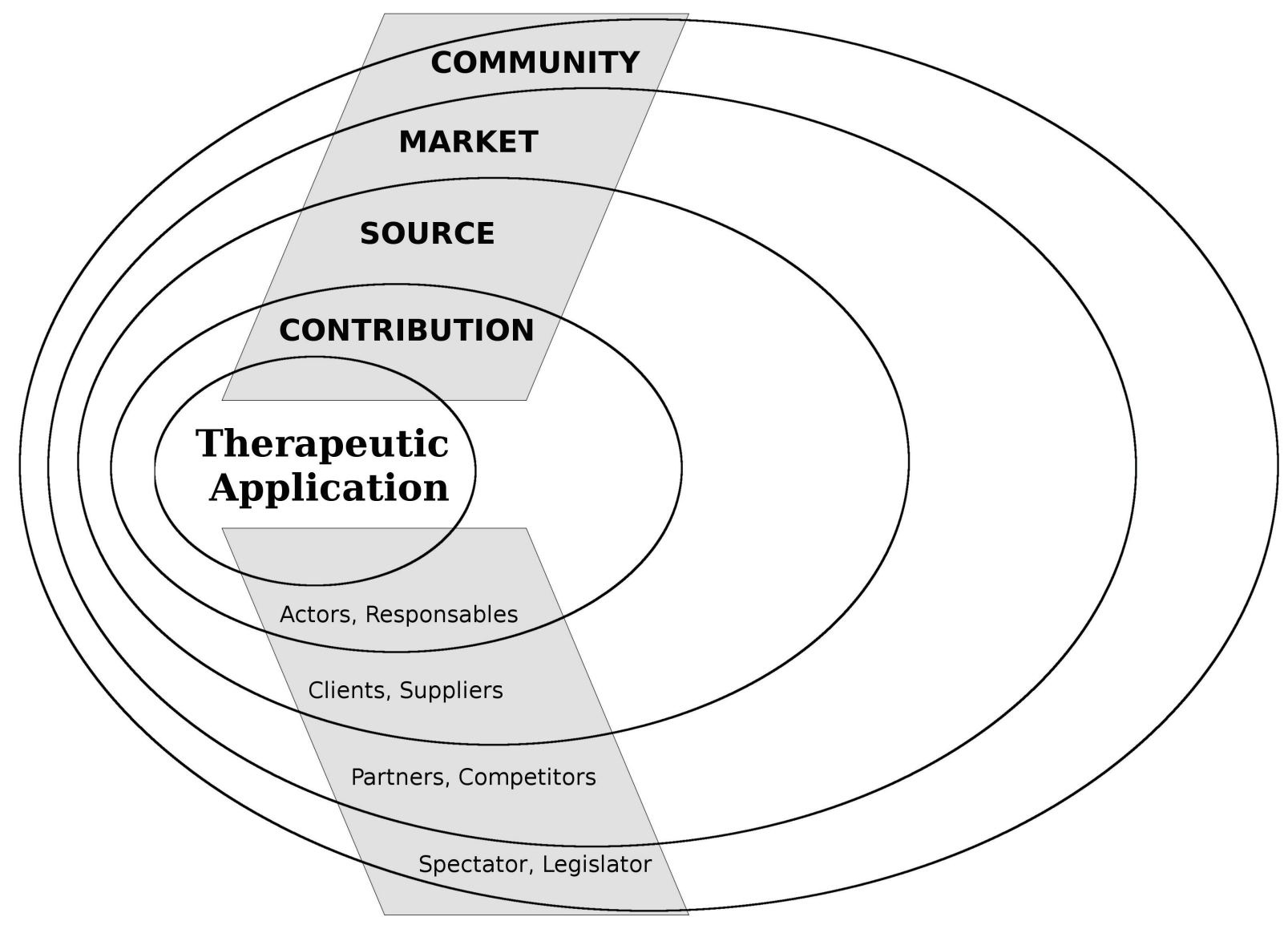

Fig. 2. Artifact for identifying the stakeholders in the design solution.

(possibly the patients), the problems which the application should address, and identify and discuss possible solutions for each problem. The Organizational Semiotics' Evaluation frame should be used at this step. It allows the design team to identify each of the stakeholders' interests, concerns, and problems regarding the solution. Furthermore, it allows the design team to identify existing requirements present in possible solutions, how they will affect the proposed solution, and how to address them.

Fig. 3 presents a possible instantiation of the Evaluation Frame. The instantiations allow the design team to identify end-users (patients), problems (clinical profile and possibly others), and possible solutions (ideal treatment and possibly others) for therapeutic applications. 


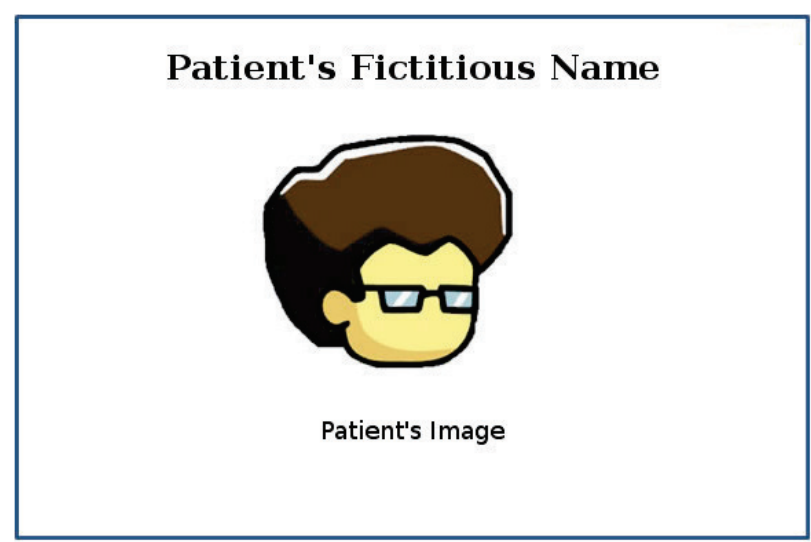

(a)

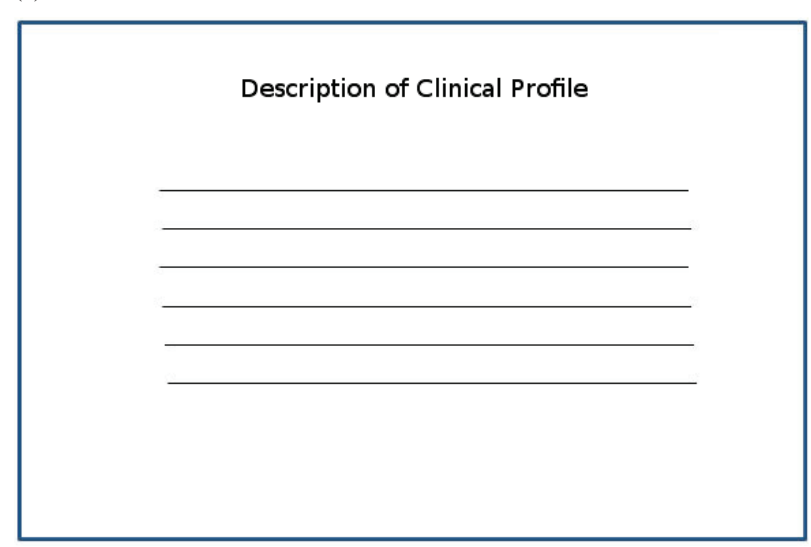

(c)

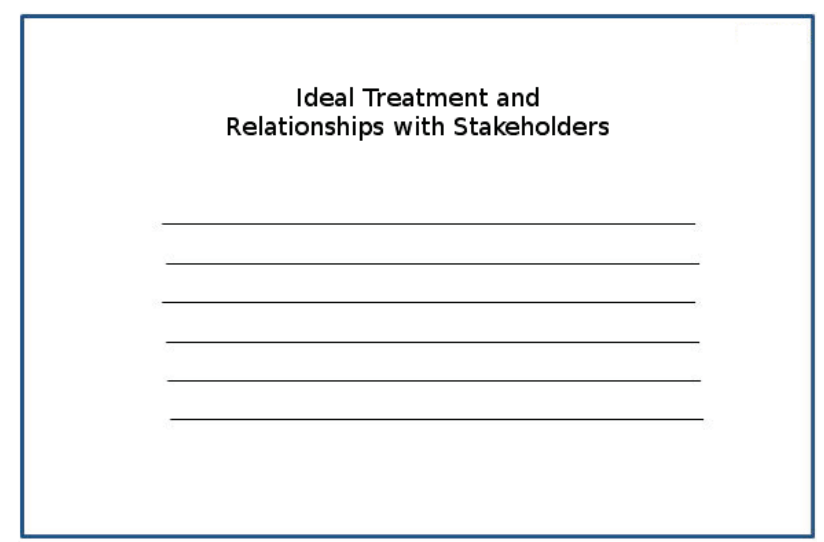

(b)

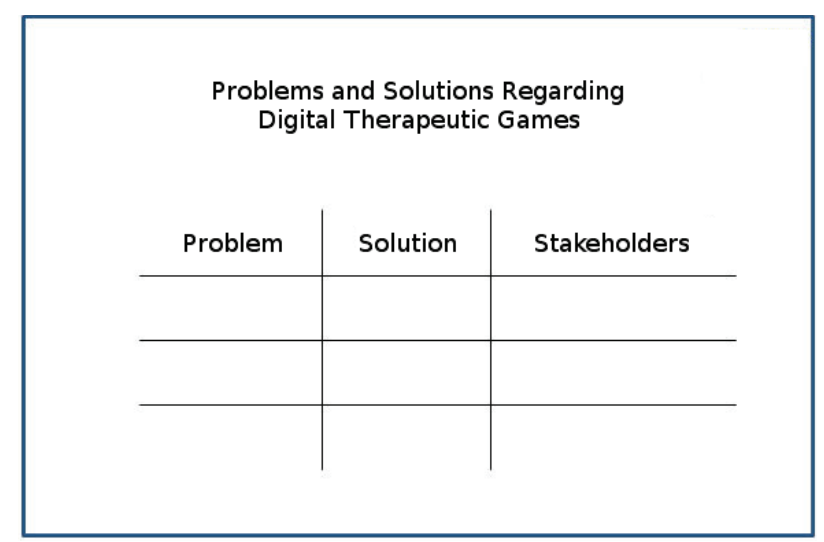

(d)

Fig. 3. Design Artifact for characterizing the end-users of the therapeutic application.

The stakeholders should fill Fig. 3's instantation according to their opinions and desires regarding the therapeutic application. For instance, the design team could use a cardboard with four different sheets, containing:

- Fig. 3 (a): a set of person's graphical representations (photos or drawings), clothes, and accessories. On this sheet, the stakeholders should create a fictitious avatar representing their conception of an end-user of the system. The design-team may provide drawing material to allow the stakeholders to further characterize their avatar, with whatever they find relevant.

- Fig. 3 (b): text field on which healthcare professionals should describe the clinical profile of a fictitious patient.

- Fig. 3 (c): text field on which healthcare professionals should detail an ideal treatment procedure to the given clinical profile. They also may detail how different stakeholders affect the procedure.

- Fig. 3 (d): table used to identify problems existing on the use of a therapeutic application, and possible solutions. The design team and stakeholders discuss possible problems regarding the end-users and most influential stakeholders may have using the application. They also identify possible solutions for each raised problem.
3) Creating the Personas: As this point, the design team knows the stakeholders, and has characterized the end-users, the problems which should be addressed by the application and possible solutions for each problem. Before creating the Personas, the design team should incorporate relevant information available in the Literature to the gathered data regarding the end-users. The goal is to achieve a sociotechnical vision regarding the end-users, which aids the design team to understand the problem domain and the context of the solution.

With the resulting information, the design team may start creating the Personas. To create the Personas, they should follow an extended version of Cooper's Personas Process. For Cooper's Personas Process' Familiar Planning phase, the design team should use the combined information of the previous two steps with the Literature study as the gathered data.

At the end of the Familiar Planning, the design team shall have enough information to characterize different user profiles. This allows the construction of the Personas' skeletons, effectively instantiating the second phase of Cooper's Personas Process (Conception and Gestation).

Afterwards, the computer science members of the design team should tweak the resulting Personas' skeletons. Should 
they consider the need of new Personas to map the gathered data, they should create and tweak them. The resulting Personas will correspond to the focus group of the therapeutic application. At the end of this step, designers and programmers should meet and know the Personas. This corresponds to Cooper's Personas Process's Birth and Maturation, marking the transition between creation and preparation for using the Personas.

4) Presenting and Validating the Personas: After creating Personas, the design team presents them to the healthcare professionals. Each healthcare professional, individually, must carefully analyze and evaluate each Persona of the focus group. The healthcare professionals register their evaluation into an evaluation form (Fig. 4), comment whether each Persona's data is correct, and whether their representation correspond to the reality. They may provide comments regarding their opinions, or suggest modifications, corrections or improvements to further enrich the Persona.

The goal of the form is to discover whether, for each Persona,

- The life history, clinical, and familiar profiles match and are coherent to real ones;

- Their representing photo or image resemble their real physical appearance;

- The professional would like to include further information or modify existing ones;

- The professional would like to leave comments or recommendations to the computer science team.

\section{Creating Personas To Represent Chemical DEPENDENCY AND DEPRESSIVE PATIENTS}

As we stressed in this paper, it is important to include different stakeholders to design an effective therapeutic application. We, therefore, explored a participatory approach [34] to the design and requirement analysis.

We described our approach to creating Personas on Section III; to illustrate it, this section presents an instantation: the initial design of two digital therapeutic games using Personas. The games will serve as a complementary tool for healthcare professionals of a HEM, philanthropic hospital. The intended audience for one game are depressive patients; the second is intended for chemically dependent patients.

HEM has been offering tranquility and welfare for its patients for 66 years. At the present moment, it has 330 hospital beds, 260 of which are insured by Brazilian's public health system, the Sistema Único de Saúde (SUS). A multidisciplinary therapeutic team — with psychiatrists, psychologists, social workers, nurses, and occupational therapists - work together to treat the patients.

\section{A. Personas Process Applied to Therapeutic Game Design}

We worked collaboratively with representatives of every group of professionals in the hospital to perform steps III-1, III-2, and III-4 of the Personas Enrichment Process. The computer science members of the design team should perform step III-3 - the creation of the Personas to represent the focus group for the application.
To perform collaboratory activities, we met the healthcare professionals three times. We used Organizational Semiotic's artifacts to collect data, and to create Personas to represent fictitious patients treated in the hospital.

Instantiation of the Personas Enrichment Process: To perform step III-1, healthcare professionals helped us to fill the Stakeholder Analysis Chart to identify agents involved in the design problem and its solution. Fig. 5 illustrates the resulting artifacts in the context of depression (a) and chemical dependency (b).

The analysis of the resulting artifacts revealed that, for both depression and chemical addiction, the family is one of the main stakeholders; furthermore, it is considered a "responsible actor". Other mentioned stakeholders were: friends, neighbors, and religious groups (such as churches). Some stakeholders are partners, competitors, and/or providers depending on the time or circumstance - a context. As an example, one might consider the stakeholder "friends". Friends might be partners, when they want to help or aid the patient; competitors, when they offer drugs for chemically dependent patients, or distance themselves from depressive patients; or even providers, when they help (provide information, for instance) with the development of the design solution.

For step III-2 (which includes the Familiar Planning phase on Cooper's Personas Process), we used the artifact illustrated in Fig. 3 to collect patient's data from the healthcare professionals. For each fictitious patient, part of the collected data included: (1) his/her clinical profile; (2) the ideal treatment for his/her clinical profile; (3) his/her relationships with the stakeholders and with the healthcare professionals; (4) problems and solutions regarding the treatment and the game; and (5) fictitious image and name for the patient.

Fig. 6 illustrates some healthcare professionals working on the artifact. During the design process, the healthcare professional discussed with themselves and the design team to define the most influent stakeholders for each fictitious patient (Fig. 6 (a)). They have created the characters for the fictitious patients using the Evaluation Frame, and have added the relevant characteristics for each patient (Fig. 6 (bd)). Fig. 6 (d) illustrates the professionals with the resulting artifact: a fictitious patient named Elliot - which would, at a later step, originate the Persona Elliot.

Besides Elliot, the design team created three more fictitious patients: Maria Clara, Carmelita, and Eufrazino. Maria Clara and Carmelita represented patients with depression, whilst Elliot and Eufrazino represented patients with chemical dependency. To illustrate the resulting fictitious patients, we will describe Eufrazino. Eufrazino is a male man, with clinical profile characterized by the use of multiple psychoactive substances. He suffers from anxiety, and is impulsive; he acquired syphilis whilst living on streets. His family abandoned him. He is rebellious: he does not accept his situation, nor the treatment; he denies using drugs. His psychic symptoms include bipolarity and attention deficit (hyperactivity) disorder (ADHD). According to the healthcare professionals, his ideal treatment would include: (1) work his motivation; (2) improve his self-esteem; (3) make him value himself, others, and resources; (4) find and work his competences to change his 
1. The profile photos reminds you of focus group's patients.

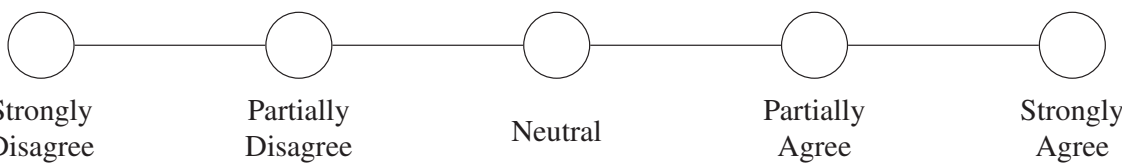

2. The life and family histories given to the Persona are coherent to the focus group's patients.

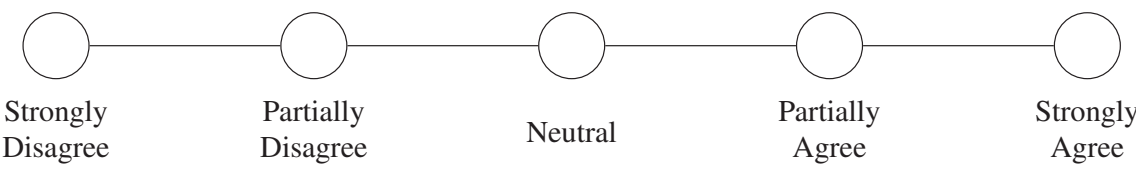

3. The clinical profile description reminds you of focus group's patients.

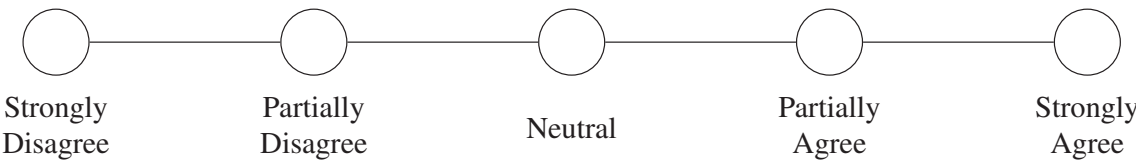

4. Would you suggest any modifications to the created Personas, or would you like to leave any comments to the design team?

Fig. 4. Personas' evaluation sheet.

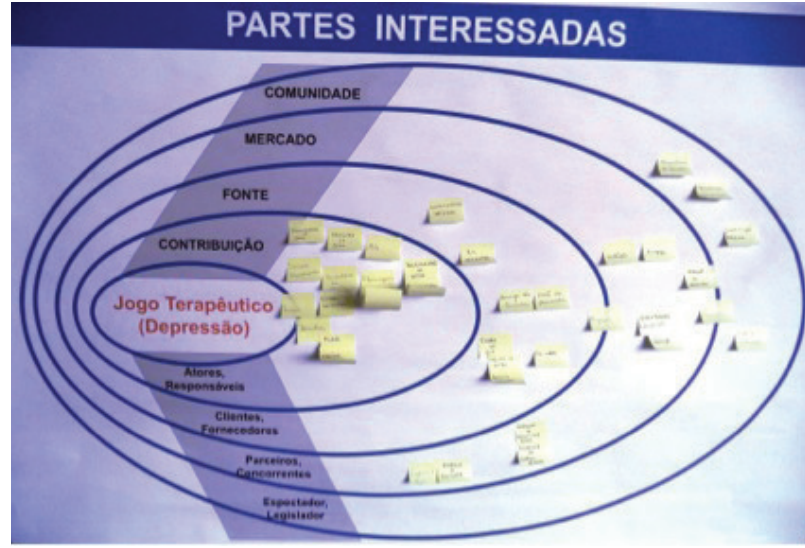

(a)

Fig. 5. Stakeholders for the therapeutic games intended to depressive patients (a) and to chemical addicts (b).

habits.

At step III-3, the fictitious characters created by the healthcare professionals became Personas skeletons. At this step, the computer science professionals researched the Literature, searching for demographic data and scientific studies to complement the data obtained in the first two steps. Two demographic studies were added to enrich the Personas skeletons: Instituto Brasileiro de Geografia e Estatsticas' (IBGE)

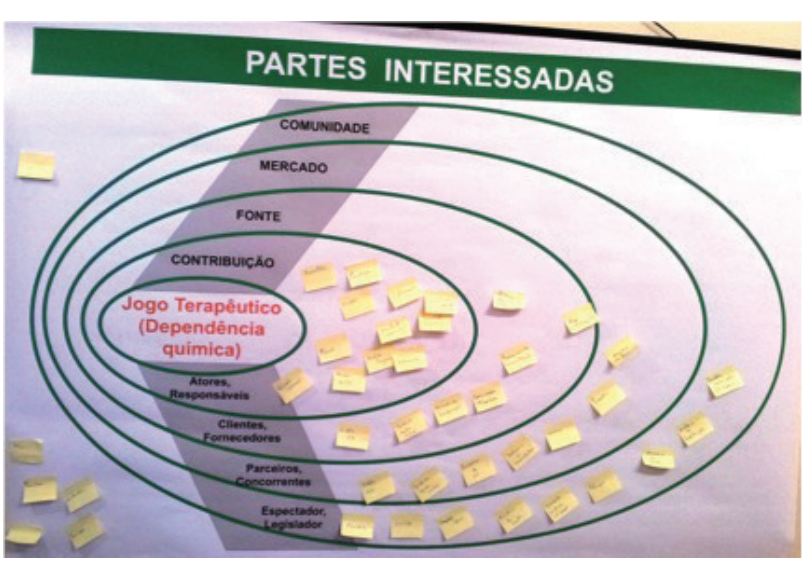

(b)

Pesquisa Nacional por Amostra de Domicílios (PENAD) [35], and Levantamento Nacional de Famílias dos Dependentes Químicos (LENAD Família) [36].

The Literature data confirmed and reinforced the healthcare professionals' information, and provided further details to complement the Personas. To incorporate the new information, during Cooper's Conception and Gestation phase, the design team created two new Personas: Frederico, with depression, 


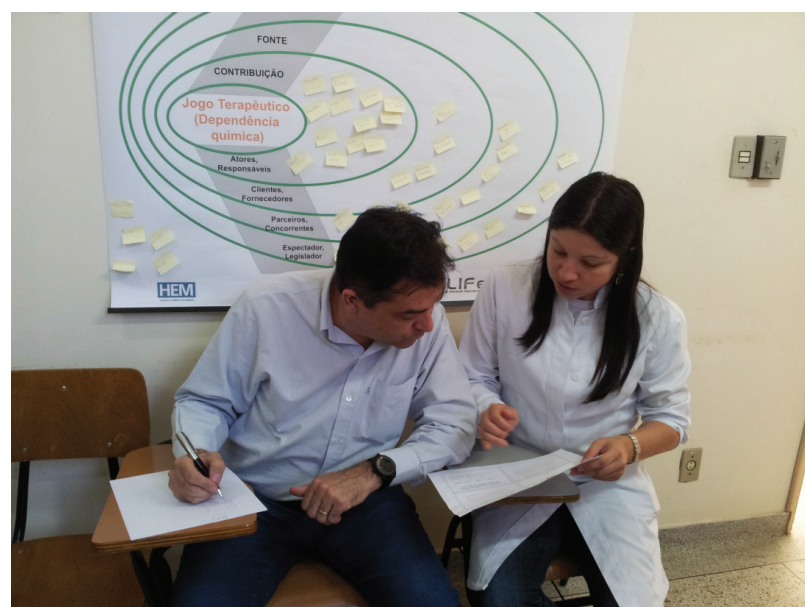

(a)

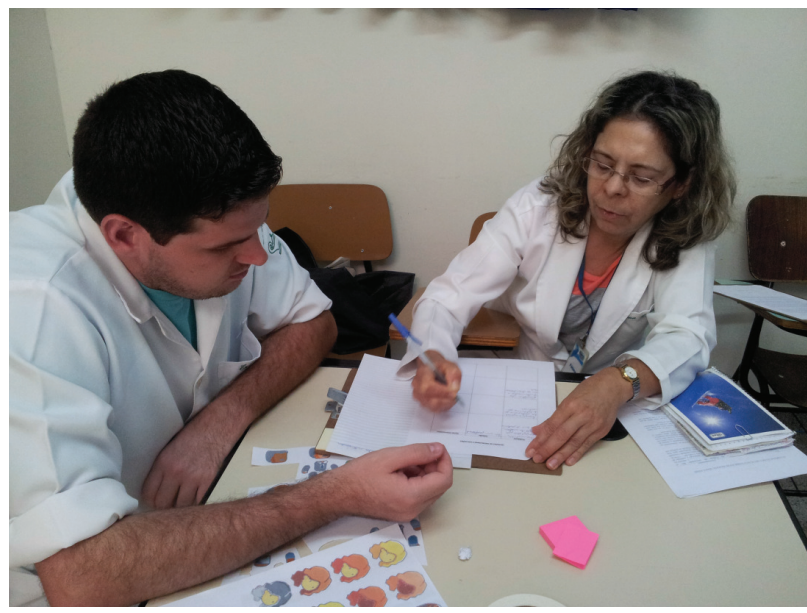

(c)

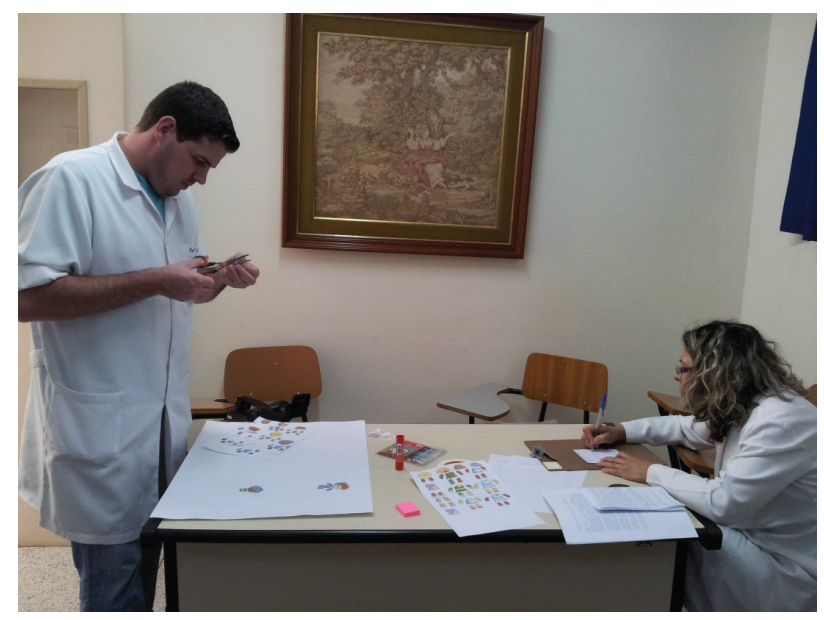

(b)

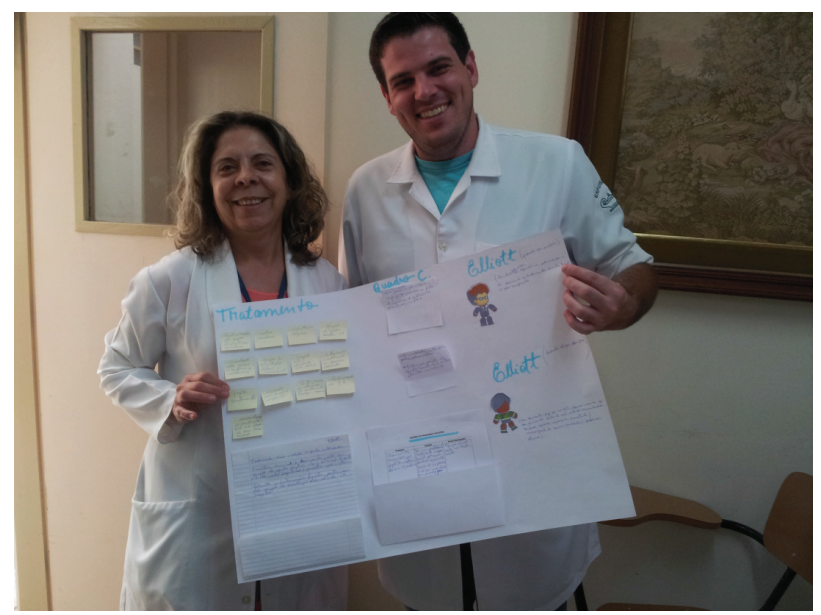

(d)

Fig. 6. Healthcare professionals contributing to step III-2 of the Personas Enrichment Process.

and Gisele, with chemical dependency.

The design team added the new information to enrich the previously defined skeletons. They organized gathered data from different fonts and categorized it to define each Persona's characteristics. At the end of the step, the design team created and enriched six Personas (the four resulting from the previous step, and the two demographic ones).

Table I illustrates a Persona skeleton, which is a combination of different data sources (participatory activities with the healthcare professionals, and demographic data). The design team used this skeleton to create the Persona Eufrazino (Fig. 7). The design team conceived Eufrazino during the Familiar Planning, and Conception and Gestation phases; and improved him at the Birth and Maturation phase. Eufrazino's slogans were defined as: "O Revoltado" ("The Rebellious"), "O Impulsivo" ("The Impulsive"), "O Morador de Rua" ("The Homeless"), and "Homen-Carneiro" ("The Sheep-Man", a metaphor for unfaithful - he "jumps over fences", like a sheep, to cheat on his wife). The design team create the slogans from terms and expressions used either by the healthcare professionals, or described in the Literature.

In Table I, the headers show the origin of the data. In Fig. 7:

- Bold text shows information gathered from participatory activities with healthcare professionals. The design team incorporated this data after summarizing the resulting artifacts from the activities. The Evaluation Frame provided Clinical profiles, and physical, cognitive, and behavioral aspects of the patients. The Stakeholder Analysis Chart provided family information, and how the person arrived at the Hospital (Pronto Atendimento de Saúde Mental PASM).

- Italic text shows data from demographic studies. This includes, for instance, age, ethnicity, education, residence, period of chemical dependency.

- Underlined text shows data from mixed sources, that is, both from participatory activities and the Literature. This data originally came from participatory activities and Semiotics artifacts, and demographic studies confirmed them.

Fig. 8 presents another Persona: Carmelita. The text styles 
TABLE I

EufraZino (Fig. 7), A PERSONA WITH CHEMICAL DEPENDENCY. THE INFORMATION TO CREATE HIS SKELETON CONTAINS DATA FOR DiFFERENT SOURCES (PARTICIPATORY ACTIVITIES, AND DEMOGRAPHIC DATA).

\begin{tabular}{|c|c|c|c|c|c|c|c|c|}
\hline \multicolumn{9}{|c|}{ Persona Skeleton (Chemical Dependency) } \\
\hline \multicolumn{9}{|c|}{ EUFRAZINO } \\
\hline \multicolumn{9}{|c|}{ Demographic Data (LENAD Família [36]) } \\
\hline Gender & Age & Education & $\begin{array}{l}\text { Ethnic } \\
\text { Group }\end{array}$ & $\begin{array}{l}\text { Marital } \\
\text { Status }\end{array}$ & Profession & Residence & $\begin{array}{l}\text { Does the Persona have } \\
\text { children? }\end{array}$ & $\begin{array}{l}\text { How long } \\
\text { has the Persona } \\
\text { been chemically } \\
\text { dependent? }\end{array}$ \\
\hline Male & $\begin{array}{l}32 \\
\text { years } \\
\text { old }\end{array}$ & $\begin{array}{l}\text { Incomplete } \\
\text { elementary } \\
\text { school }\end{array}$ & Black & Married & Unemployed & $\begin{array}{l}\text { Living on } \\
\text { streets for } \\
\text { two years }\end{array}$ & $\begin{array}{l}3 \text { children, each of each } \\
\text { with a different woman; } \\
\text { he has not assumed pa- } \\
\text { ternity for any. }\end{array}$ & $\begin{array}{l}8 \text { years, approxi- } \\
\text { mately }\end{array}$ \\
\hline \multicolumn{9}{|c|}{ Demographic Data and Participatory Practise } \\
\hline \multirow{2}{*}{\multicolumn{3}{|c|}{$\begin{array}{l}\text { Psychoactive Substances Consumed } \\
\text { Crack, cocaine, and marijuana }\end{array}$}} & \multirow{2}{*}{\multicolumn{3}{|c|}{$\begin{array}{l}\text { Related Psychiatric Conditions } \\
\text { Anxiety, impulsiveness, hyperactivity, } \\
\text { and aggressivity symptoms. }\end{array}$}} & \multirow{2}{*}{\multicolumn{3}{|c|}{$\begin{array}{l}\text { Required Hospitalizion } \\
\text { Pronto Atendimento de Sade Mental (PASM) }\end{array}$}} \\
\hline & & & & & & & & \\
\hline \multicolumn{9}{|c|}{ Participatory Practise } \\
\hline \multicolumn{3}{|c|}{ Family Profile } & \multicolumn{3}{|c|}{ Hospital Arrival Description } & \multicolumn{3}{|c|}{ Miscellaneous Characteristics } \\
\hline \multicolumn{3}{|c|}{$\begin{array}{l}\text { He was married, and had one child. } \\
\text { He divorced his wife. After cheating on } \\
\text { her several times, his wife expelled him } \\
\text { from home. He had decided to live on } \\
\text { streets since. }\end{array}$} & \multicolumn{3}{|c|}{$\begin{array}{l}\mathrm{He} \text { arrived at the hospital through } \\
\text { PASM. When he arrived, he was dirty, } \\
\text { almost nude, thin, aggressive, body } \\
\text { wounded (his hands were especially } \\
\text { wounded), and had syphilis. }\end{array}$} & \multicolumn{3}{|c|}{$\begin{array}{l}\text { He has active sexual life, and visits promiscuous places and } \\
\text { environments. He is impulsive, competitive, and does not accept } \\
\text { rules or norms. He does not accept any treatments, either. He } \\
\text { is rebellious, and considers that society is unfair. He feels } \\
\text { abandoned. }\end{array}$} \\
\hline
\end{tabular}

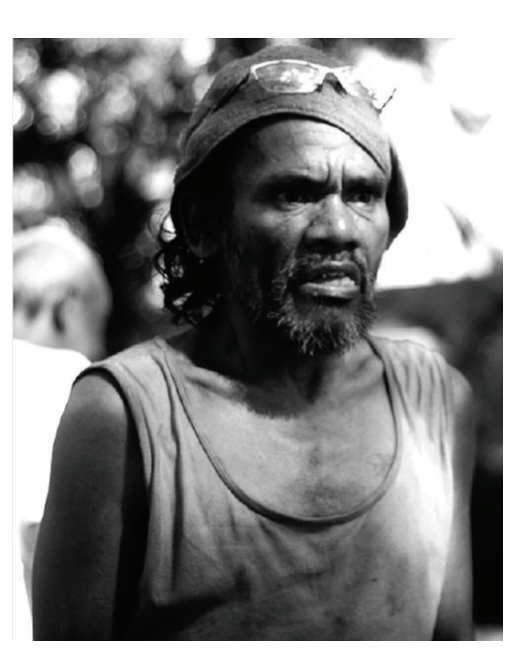

\section{EUFRAZINO}

Eufrazino is 32 years old. Earlier this year, he has started his rehabilitation treatment to chemical dependency. He is black, has studied until the $6^{\text {th }}$ year of elementary school. He has been chemically dependent for, approximately, 8 years.

Eufrazino is married. Although he has 3 children, only one is his wife's, due to adultery. He used to date several women, and to visit promiscous places. In one of his visits, he has acquired syphilis and started consuming marijuana and cocaine.

Due to his behavior, Eufrazino's wife expelled him from home. Afterwards, he lived on the streets for about 2 years. When living on the streets, he started using crack as well as marijuana.

He was taken to the Pronto de Atendimento de Saúde at the beginning of this year. When he arrived there, Eufrazino was almost nude. He was very thin, and badly wounded - his hands were especially wounded.

Eufrazino is anxious, impulsive, hyperactive, aggressive, and competitive. He does not accept rules nor norms; he refuses his treatment, and is rebellious with society: he believes that it is unfair. He feels abandoned and alone.

Fig. 7. Eufrazino's resulting Persona.

used to convey the data source are the same as above. Carmelita represents a fictitious depressive patient. The design process to create her was similar to Eufrazino's: the design team conceived her at Familiar Planning, and Conception and Gestation phases, and improved her at Birth and Maturation. Carmelita's clinical profile describes lack of will to work, muscle pain, and her family's difficulty to understand her condition.

After the design team created the Personas, the Personas Enrichment Process reached its step III-4. At is beginning, the Personas were still in Cooper's Maturation phase. The design Team reunited with the healthcare professionals once again: this time, to evaluate the Personas (Fig. 9).

Eight professionals participated in the evaluation: four evaluated the enriched Personas representing depressive patients; the remaining four, ones representing chemical dependent patients. They evaluated both the enriched version of the four original Personas skeletons, and the two new ones, created exclusively based in Literature data. The goal of the evaluation was to allow professionals to verify the correctness of each persona, whether the included demographic data matched their reality, and whether the chosen images were compatible and accurate. After the evaluation, the professionals had to validate each Persona, approving them to use as end-user 


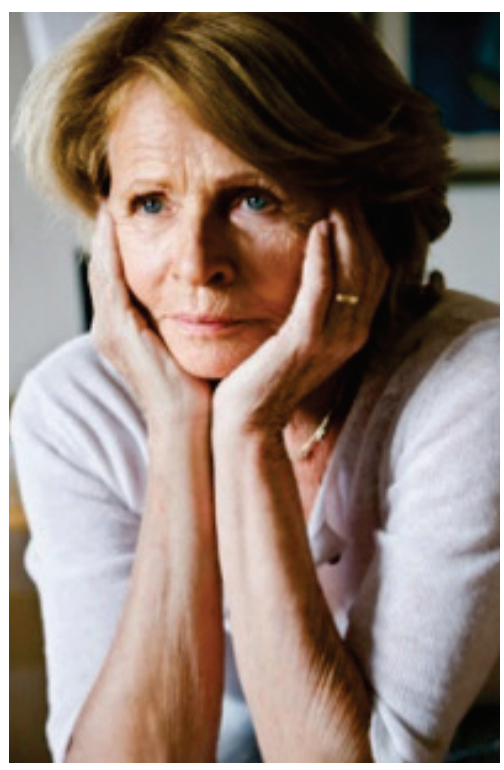

\section{CARMELITA}

Carmelita is 58 years old. She is an independent tailor, recognized in her neighorhood for her work. Carmelita is a housewife, taking care of her house, cooking, and taking care of her husband and youngest child. Carmelita has been feeling unhappy, discouraged to work for a while; this was causing her to delay her work. A recent tragedy has worsened her condition: her oldest son died due to a heart attack. Carmelita herself found him dead. To aggravate her situation, her youngest child is chemically dependent; he often does not send her news for days.

Carmelita says she has problems to sleep, suffers muscle pain, and feels discouraged and deeply sad. She smokes excessively, and is alone most of the day, as her husband, albeit retired, works unregistered to complement the family income. After a medical appointment, she was forwarded to a psychiatrist, who diagnosed her depression. She does not have access to technology in general.

She suffers resistance and prejudice from her family, who opposes her treatment to depression. Her husband, in special, is her main opponent, as he does not know the seriousness of depression and the need for treatment.

Fig. 8. Carmelita's resulting Persona (representing a fictitious depressive patient).

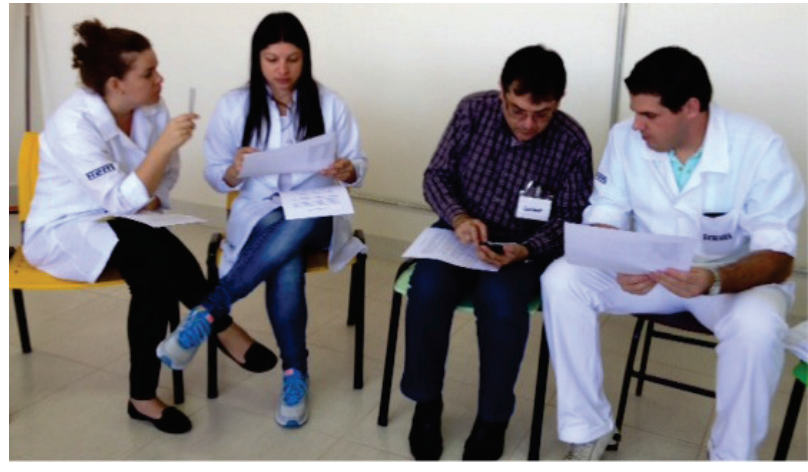

Fig. 9. Healthcare professionals evaluating the Personas.

representations for the game design. The professionals could suggest fixes and improvements to the Personas.

Each healthcare professional answered the questions from the evaluation form previously shown in Fig. 4. For the depressive Personas:

1) Regarding the profiles' photos. Three of the evaluators partially agreed with chosen photos for the Personas. The remaining one strongly agreed with the photos.

2) Regarding the family history profile and context. Three of the evaluators partially agreed with the definitions; the last strongly agreed.

3) Regarding the clinical profiles. One of the evaluators partially agreed with the clinical profiles for the Personas. The other three strongly agreed.

The evaluators left suggestions for modifying and improving the Personas to answer the fourth question. For instance, regarding the photo, the patients usually had "more debilitated appearances, often due to the lack of care and to their social class", and, regarding the family history, "usually, the life history has more aggravating factors and difficulties on familiar dynamics".

For the chemically dependent Personas:

1) Regarding the profiles' photos. Three of the evaluators strongly agreed with the chosen photos for the Personas. The remaining one strongly agreed with the photos.

2) Regarding the family history profile and context. Three of the evaluators partially agreed with the definitions; the last strongly agreed.

3) Regarding the clinical profiles. One of the evaluators partially agreed with the clinical profiles for the Personas. The other three strongly agreed.

The last question illustrates how open questions allows stakeholders to give feedback regarding their issues or to suggest changes to continuously improve the Personas. An example of suggestion was that "The patient Gisele would be more realistic without the diagnosis of Obsessive-Compulsive Disorder". The healthcare professionals, based on the Persona's description and their domain expertise, suggested an improvement to make the Persona more realistic.

As a second example, they suggested that "regarding Elliot, [the design team] could add a tattoo" to his appearance. In this case, although the change was to the physical appearance of the Persona, it also provided insights to improve its personality, behaviors, and habits. Thus, the suggestion allows the design team to consider new scenarios and activities on which this Persona might participate.

Finally, during the validation, the healthcare professionals suggested changes to the images and informations attributed to the Personas. For instance, regarding the Persona Eufrazino, they suggested to: (1) add references to previous visual and hearing hallucinations; and (2) add further characterization to 
physical traits and habits, such as poor hygiene and muscular mass loss.

The design teams made the suggested changes to the Personas. At the end of this step of the process, the Personas were close to the Adulthood phase, ready to be used on the game design activities.

\section{B. Patients Characteristics versus Treatment versus Game Characteristics}

Other than helping in the creation of the Personas, the participatory practices showed the design team the differences between patients with depression and patients with chemical dependency. For instance, each group had different characteristics, behaviors and needs, and they had different responses to the treatment. The stimuli employed to treat the patients are different as well. Therefore, exploring a single genre or the same game mechanics to create a single therapeutic game for both groups could be ineffective: it would not adequately address the specificities of the required treatments.

In this context, the design team chose to create two different games: one game for each condition. The participatory activities - and the Personas creation - outlined recurring patterns for each group. Some of these patterns included the conditions' symptoms and treatments, and the stimuli employed for each treatment.

According to the healthcare professionals, depressive patients usually have low self-esteem, suffer from daily stressful situations (either at work and/or with the family), have lost family members, live in urban areas, and/or have financial problems. The patients usually lose their will to live, become sad, feel they are not understood, have difficulty to sleep, feel body pain, and cry easily. At later stages, the patients stop taking care of their physical appearance and daily activities and habits, including hygiene.

The hospital's treatment to depression includes, among others, the use of medications, individual psychiatry, group occupational therapy, family care, and social, daily life and physical activities. An important goal of the treatment is to encourage self-esteem improvements and motivating the patients to live and resume their daily activities. Thus, according to the healthcare professionals, a therapeutic game should aim improving the patient's self-esteem and provide stimuli to the practise of forgotten or currently ignored activities, such as hygiene care. They recommended the games should be dynamic, fun, colorful, and active - if possible, the patients should move their bodies whilst playing.

According to the healthcare professionals, chemical dependent patients, on the other hand, usually arrive at the hospital poorly dressed, dirty, wounded, confused, with low body mass, several clinical issues, and, at times, with sexually transmitted diseases (STDs). The patients have trouble dealing with the reality: they live in a "parallel world", and do not accept orders from others - especially for their family. They want immediate results on whatever they do; if they cannot achieve what they want, they consider themselves failures. However, if they do, they feel that they are the very best at the task. They are usually anxious, rebellious, refuse treatment, deny using drugs, trouble with family members loss, and feel abandoned, needy, misunderstood and lacking family love. Sex is strongly present in the lives of the patients: at times, it is used as a way to obtain drugs. According to the hospital's psychiatrists, many patients use more than a kind of psychoactive substances, including alcohol. Many times, they are, among others, bipolar, have ADHD, and/or oppositional defiant disorder (ODD).

The hospital's treatment for these patients starts with a reception: the professionals welcome them, and help them with personal hygiene and treating their wounds. Afterwards, the professionals work on detoxification of the patients, followed by therapies to control abstinence and anxiety. Therapies aim to improve motivation, self-esteem, ethics, self-value, valuing others, and working on the patients competences to change their habits, social skills, humanity and respect, and how to deal with divergence.

Regarding therapeutic games, the professionals advise caution: they ought to be used carefully to avoid exchanging a dependency (chemical) by another. They recommended supervisioned playing sessions, allowing an experienced healthcare professional to monitor how the patient played the game. As the patients are anxious, they recommended a dynamic game. The game should show that it is not always possible to win; however, that a loss is not the end, but a new beginning. Patients should learn with losses, and use the acquired knowledge to go further than they could before, explore new possibilities, or change plans. Furthermore, the professionals hope the game helps the patients to recover health and correct principles and behaviors lost by the use of drugs.

As the previous paragraphs suggest, comparing depressive to chemically dependent patients highlights the differences and peculiarities of the individual and therapeutic needs. One could go further and compare specific needs for gameplay, such as response time, tolerance to repetitions, and sensory stimuli needs (visual, aural, or tactile). Thus, to satisfy the requirements, therapeutic games should be as flexible as possible.

\section{Personas-Driven Therapeutic Game Design}

The Personas Enrichment Process offered a sociotechnical vision to characterize possible end-users of therapeutic applications. Considering the context of mental health, the process synthesizedinformation from different sources and stakeholders on six different Personas. Each persona symbolizes information such as the clinical profiles of the patients, and relations of patients with the stakeholders and technology. Therefore, at this point, the existing Personas are able to aid the design team on making conscious choices regarding the design. The Organizational Semiotics' artifacts explored also provides further information, and allow the team to anticipate problems and work to address them.

To illustrate the usefulness of the Personas, this section describes how we used them to design two therapeutic games. The intended audience for the first game are patients with depression; the second, patients with chemical dependency. Table II exemplifies some characteristics of the patients and context, and how they brought evidences to the game's design. For instance, considering depression, if the patient has low 
TABLE II

EXAMPLES OF CHARACTERISTICS OF THE CONTEXT AND OF THE PATIENTS (PERSONAS), AND EVIDENCES FOR THE GAME'S DESIGN.

\begin{tabular}{|c|c|c|}
\hline & Depression & $\begin{array}{l}\text { Chemical } \\
\text { Dependency }\end{array}$ \\
\hline $\begin{array}{l}\text { Patient and } \\
\text { Context } \\
\text { Characteristics }\end{array}$ & $\begin{array}{l}\text { The patient arrives } \\
\text { with low self-esteem, } \\
\text { low disposition, and } \\
\text { constant sadness. } \\
\text { The therapists lead so- } \\
\text { cial activities, and daily } \\
\text { living activities. }\end{array}$ & $\begin{array}{l}\text { The patient arrives } \\
\text { poorly dressed, } \\
\text { dirty, body wounded, } \\
\text { confused, aggressive, } \\
\text { and does not accept } \\
\text { orders or opinions. } \\
\text { His/her family is away. } \\
\text { The therapists clean } \\
\text { the patient, cure his/her } \\
\text { wounds, and apply } \\
\text { practices to control } \\
\text { his/her abstinence and } \\
\text { anxiety. }\end{array}$ \\
\hline \multirow[t]{2}{*}{$\begin{array}{l}\text { Evidences } \\
\text { Design } \\
\text { Game }\end{array}$} & $\begin{array}{l}\text { The game should pro- } \\
\text { mote good behaviors, } \\
\text { daily living, physical } \\
\text { movements, and be dy- }\end{array}$ & $\begin{array}{l}\text { The game promote eth- } \\
\text { ical values, skill to en- } \\
\text { able change of habits, } \\
\text { humanity, and respect. }\end{array}$ \\
\hline & namic and colorful. & $\begin{array}{l}\text { The game should } \\
\text { promote self-esteem } \\
\text { improvements, allow } \\
\text { the patient to value } \\
\text { himself/herself and } \\
\text { other, promote social } \\
\text { skills, and help he/she } \\
\text { on dealing with } \\
\text { divergences. }\end{array}$ \\
\hline
\end{tabular}

self-esteem and constant sadness, the healthcare professionals employ social activities. The game should reflect this situation, by encouraging daily living behaviors, redemption of the selfesteem, and have dynamic activities, with colorful graphics.

Considering the user characterizations and their needs, the design team defined the game styles based on the Personas. For the chemical dependency game, the design team chose a combination game mechanics from the action, adventure and role-playing game genres. In order to give freedom to the patient explore the world, the design team chose an open world (or sandbox) genre. The game allows the patient to follow either a lawful path, doing ethical activities, or a chaotic path, causing harm to himself and/or others. It is important to provide both options to show how actions and choices can change the life of the patient - either for better, or worst. Depending of his/her action, the patient earns points (for good, lawful choices), or lose points (for bad, harmful choices). However, the design avoids sudden or unfair losses - this way, it offers the patient a chance to recover, by trying another (hopefully better) path.

For the depression game, the design team chose a game with simple interactions. The emphasis was to work on patients' motivation, showing how daily living choices and activities can improve the patients' mood - and their life quality. The game provides colorful, cute graphics, with cheerful songs. There are no loss conditions in it; rather, the game flow provides a guided session, in which the patient can play with the available elements to customize an avatar. They can choose, change, and improve its appearance according to their personal tastes.

Moreover, Personas aided and guided the design on more specific choices. Fig. 10 shows a DR containing ideas regarding how to represent the chemical dependency game's main character. The bold text options shows the chosen path. In this DR, the design team dealt with the problem (represented as a Question - Q in the figure) of how to physically represent the character in the game. Initially, the design team considered as options $(\mathrm{O}$, in the figure) anthropomorphic and non-anthropomorphic figures. For the latter, they considered idealized characters, such as animals or superheroes. After the design team analyzed and discussed the design problem, they rejected the non-anthropomorphic options. They argued that this kind of representation would not convey fidelity to patients' daily life scenarios; therefore, they would not arouse the expected stimuli.

The design team, therefore, opted for anthropomorphic figures. They envisioned two different options: humanoid figures, or figures with human traces. They opted for the former, reasoning that a character with human appearance would ease the identification - and own projection - of a patient with his/her character. For figures with human appearance, the design team considered two options: flexible, or non-flexible representation. Patients would be able to customize flexible figures according to their preferences. Conversely, non-flexible representations would not allow modifications - they would follow the representation created by the design team.

To increase the chances of self-identification of patients with their character, the design team opted for flexible representations. Their reasoning was that, to reinforce and promote the identification, the patient should be able to customize the character according to his/her preferences, by choosing, for instance, the ethnicity, and hair style. Furthermore, flexible representation allowed for better gameplay customization and stimuli. For instance, they would enable the design team to: (1) modify physical and hygiene aspects of the character; (2) change sociability aspects, such as his/her relationships with friends and family. The design team considered these criteria $(\mathrm{C}$, in the figure) as positive goals for the game.

The appearance of the character may change according to the patient's choices and actions. For instance, Fig. 11 illustrates a healthy character (a), and an unhealthy character (b). The character may change gradually from the former to the latter, should the patient choose to consume in-game drugs. As (b) suggests, the character may suffer the effects described in the Personas, such as becoming wounded, dirty, and poorly dressed - he/she starts to lose what they have (healthy, money, material possessions, friendships) due to the addiction.

Due to the willingness of chemically dependent patients to give up after an unsuccessful try, the Personas influenced the scoring system of the game. The goal is to show how the player is progressing according to his/her choices and actions. At the top of Fig. 12, there are several images to represent different in-game attributes. The green one, with a dollar bill icon, symbolizes the financial status of the character. The blue one, with a pulsing heart, represents his health. The yellow one, with a heart, represents friendship, and varies according to whom he is talking to - it is the characters' relationships with family, friends, and the society. 


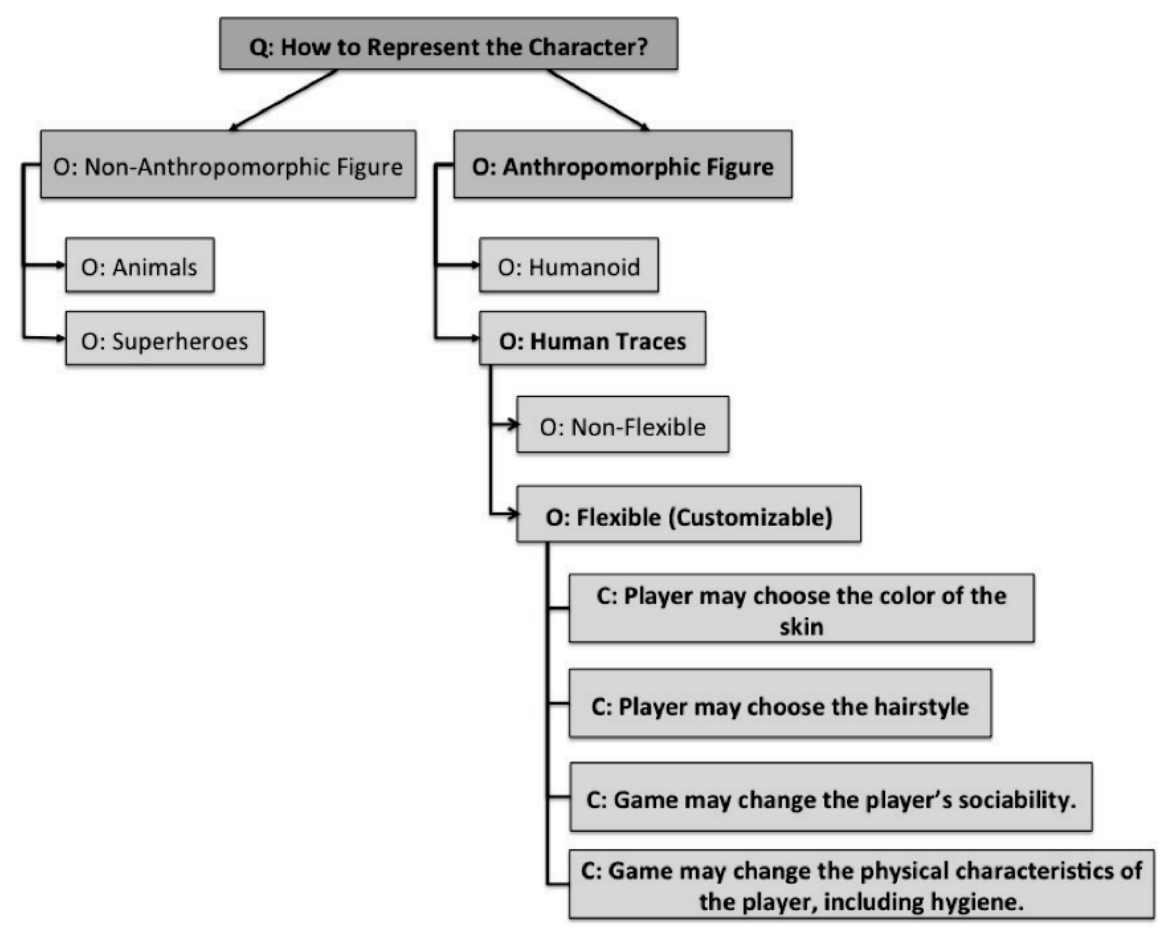

Fig. 10. DR regarding the decisions of how to represent the game for chemical dependent patients. Bold text show the chosen options.

In-game choices determine how these parameters change. For instance, in a supermarket scenario, he/she might work to earn money. Afterwards, he/she might spent the money to buy different items or services (including clothes, items, and even drugs). In a different scenario, such as a bar (Fig. 12), he/she might drink, which reduces his/her health, and money; socialize, which might raise his/her friendship; or even steal, which raises the money and decreases everything else. Should the character go to the hospital seeking treatment, his/her health increases.

Furthermore, in Fig. 12, the dialogue shows a conversation of a character selling in-game drugs ("barato bom", roughly "good stuff"). The dialogue shows two features based on the Personas: use of the patients' habitual language, and giving $\mathrm{him} /$ her the power of choice. The patient may choose to accept (buy) or to refuse the offer. Should they accept the offer, it would be the real-life counterpart of consuming drugs - in the game, this decreases all the character's status.

Finally, the current values of the parameters provide or remove choices and freedom to the character. For instance, without money, the character cannot purchase goods. Without money and with bad friendship with family, friends, and the society, the character cannot find a significant other. Low health and bad friendship negatively affect other scenarios, such the bar and hospital. The game ends if the character passes out due to exhausting his/her health.

For depression, the created Personas suggested the need for an easy to interact game, due to the lack of digital familiarity of some patients. Highlighted characteristics identified in the Personas, such as low self-esteem and sadness, guided the design process. Trying to increase the self-esteem, and to promote happy thoughts, the design team opted for colorful images, cheerful sound effects and songs, and positive messages for in-game achievements.

Fig. 13 illustrates a scenario to promote personal healthcare habits to depressive patients. It represents a beauty salon, on which the patient is asked to dress a character to an activity (such as a party or a walk at the sea). The patient may choose clothes, shoes, and a hairstyle for the character. The goal is to exercise dressing as a daily living activity. Fig. 13 (a) illustrates a female character; in it, the patient has already chosen the desired hair and clothes: it is now time to choose the shoes. When the patient finishes the dress-up, the game displays a positive reinforcement message ("se cuidar faz bem!" on the image, that is, "taking care of yourself is good for you!"). Other scenarios promote other activities, such as taking care of others, having fun, and learning something new.

\section{CONClusions ANd Future Work}

Technological development brings new opportunities for scientific progress. Due to its importance, healthcare can benefit from new technologies or improvements to existing ones. Tools and applications to aid the professionals in their practices can help patients and themselves alike. Particularly, digital systems may provide additional feedback regarding the treatment to the professional, and help the patients to recover faster, or to stick with the treatment.

However, healthcare applications need to be carefully designed and evaluated: at the worst case, design errors may cost human lives. Therefore, the development of therapeutic 


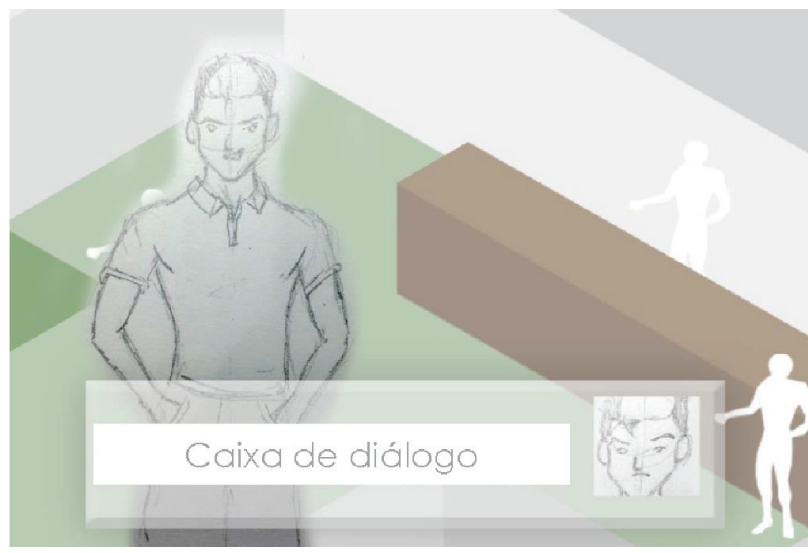

(a)

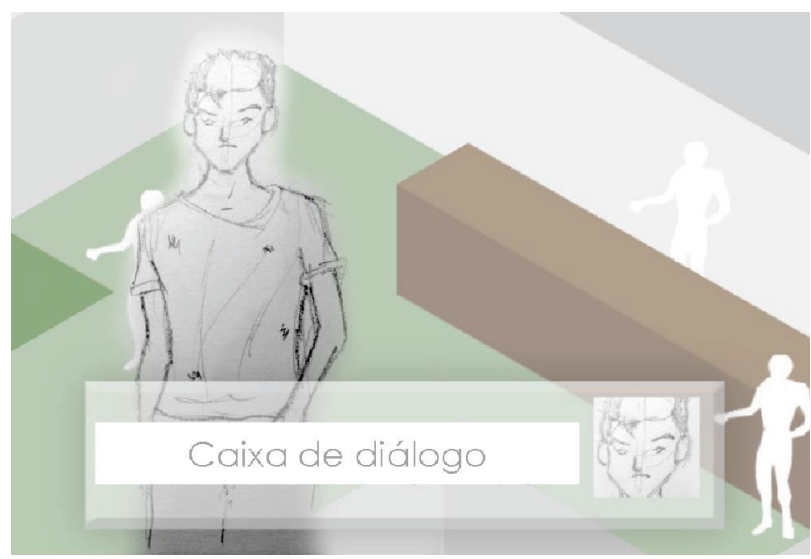

(b)

Fig. 11. Graphically conveying changes to the physical condition of the main character in the game for chemically dependent patients. (a) Healthy character (b) unhealthy character, poorly dressed, dirty, and wounded.

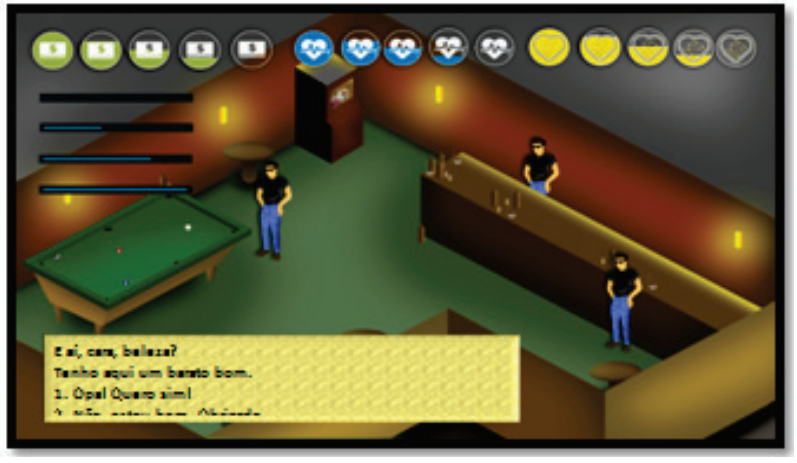

Fig. 12. Screenshot of the prototype of therapeutic game for chemical dependency (bar scenario)

applications benefit from detailed and complete requirements analysis - the more information the designers have, the better the resulting application may become.

Personas may aid designers with the requirements analysis. However, if performed exclusively by designers, the resulting Personas may lack the knowledge of different stakeholders

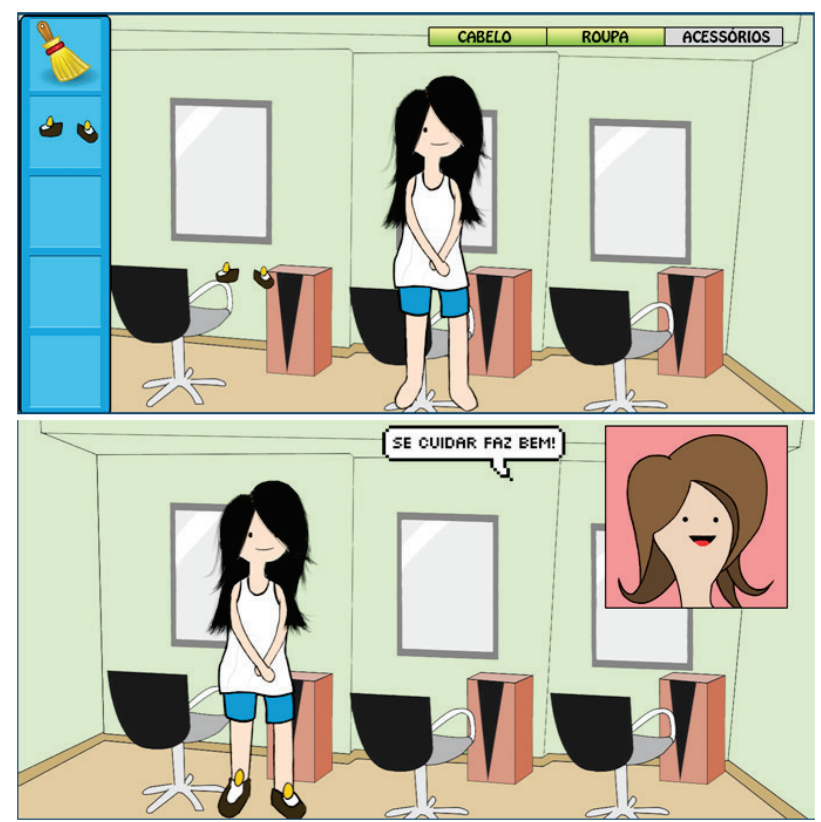

Fig. 13. Screenshot of the prototype of therapeutic game for depression.

of the healthcare domain. Therefore, to enrich the analysis, it is important to include the stakeholders and benefit from their knowledge, experience, and domain expertise. Thus, one should aim to define a multidisciplinary design team, working together with the stakeholders for the best outcomes.

Our paper followed this participatory approach. We combine Personas with participatory approaches and Organizational Semiotics' techniques and frameworks to enrich the requirements analysis. This way, the design team obtains collective and qualified information to accurately address the design problems.

To create enriched Personas, we presented the Personas Enrichment Process. The process aimed to aid in the design of therapeutic applications to mental health. In the process, a design team is defined by incorporated professionals from different knowledge areas. The process benefited from Organizational Semiotics' Stakeholder Analysis Chart and Evaluation Frame to provide a socio-technical vision regarding the design problem. The design team applied the frameworks with participatory practices, including the stakeholders to the requirements analysis process and formalizing their expertise and knowledge into design information. Including different stakeholders might even be more important when one considers mental health, as, depending on the condition, considering only the patients needs might be unreliable. As such, the Personas Enrichment Process extends Cooper's Personas Process, as it brings the sociotechnical vision and the domain knowledge present in the stakeholders, which is missing in Cooper's process.

Next, we illustrated how we applied the Personas Enrichment Process with healthcare professionals to create Personas to map chemically dependent and depressive patients. These Personas were used as basis to the ongoing design of two therapeutic games, which had as intended audience the same 
two groups of patients. The design team benefited from the expertise of healthcare professionals to identify stakeholders, understand the patients, their conditions and treatments, and even their life stories, motivations, and problems. They also helped to identify problems, propose solutions, and recommend the best alternatives and approaches for the problems.

Afterwards, the design team researched the Literature, searching for additional studies to complement the gathered information. Among the studies, they found demographic data regarding the intended audience. They confirmed many statements provided by the participatory approaches, and obtained new data. The design team used the data and studies to further enrich Personas skeletons and create the Personas. Healthcare professionals evaluated and validated the Personas, suggesting issues and improvements as needed.

Finally, the enriched Personas were ready to serve as reference and guide the design activities. We showed how the design team used the Personas to make informed decisions regarding the design of the therapeutic games - Personas guided the decisions, and Design Rationale described the thought process of the design team. Personas aided the design from high-level decisions (such as the game style, genre, and ending conditions), to low-level, specific decisions (such as game mechanics, reward and punishment, and complexity for the activities). The design team could also determine how to explore sensory information to reinforce the pretended messages (such as the use of colorful images and cheerful music).

Therefore, although one might argue that previous knowledge from the computer science designers have benefited the game design activities, the knowledge to base the choices came from the analysis of Personas. Although the designers might associate which game mechanics may work for each context, only healthcare professionals may know, in advance, whether they would be positive to the treatment. This was another benefit from the participatory activities: computer science designers could discuss considered game mechanics with healthcare professionals, which helped to filter good from bad ones, and guide the game's design.

Furthermore, the participatory activities showed the design team that, even among patients with a same condition, each patient may have different needs. For the game requirements, this reflected on decisions regarding, for instance, response time, tolerance to repetitions, and sensory stimuli. As a single set of interactions would not be enough to satisfy all users, it is necessary to build highly flexible games. This is important both to patients and to healthcare professionals themselves: they might want to modify existing settings, add new scenarios, or customize an activity to tailor a patient's needs.

At this moment, we are improving the design, creating new content and implementing the therapeutic games. A first prototype for each was implemented and played by patients, receiving good feedback. The design team is working on new scenarios, dialogues, and activities to the game. To make the game flexible to patients, we are exposing, when possible, variables to let the patients customize the game. This aims to let them adjust some aspects of the game according to their needs and/or personal preference. On the other hand, to make the game flexible to healthcare professionals, we are developing tools which allows editing and creating content for the game. The first step towards this is the inclusion of an end-user dialogue editor, to allow the professionals to create or modify dialogues and scenarios to the game.

Other than developing software solutions to aid in therapeutic practices, our research provides opportunities to observe how applications might influence user's decisions, and how they may contribute to behavioral changes. In this context, we intend, in the future, to formalize new requirements to develop of therapeutic systems, develop tools to aid the design, development, evaluation, and validating of these systems, and study how design choices might influence positive behavior changes.

\section{ACKNOWLEDGMENTS}

The authors would like to thank the healthcare professionals and administrators of the Hospital Espírita de Marília on the effective participation and contributions to this research project. We would like to thank the UFSCar's Dean of Extension for the support.

\section{REFERENCES}

[1] M. Cheung, Therapeutic Games And Guided Imagery: Tools for Mental Health And School Professionals Working With Children, Adolescents, And Their Families. Lyceum Books, Aug. 2006.

[2] M. Ma, M. McNeill, D. Charles, S. McDonough, J. Crosbie, L. Oliver, and C. McGoldrick, "Adaptive virtual reality games for rehabilitation of motor disorders," in Universal Access in HumanComputer Interaction. Ambient Interaction, ser. Lecture Notes in Computer Science, C. Stephanidis, Ed. Springer Berlin Heidelberg, Jan. 2007, no. 4555, pp. 681-690. [Online]. Available: http: //link.springer.com/chapter/10.1007/978-3-540-73281-5_74

[3] J.-H. Shin, H. Ryu, and S. H. Jang, "A task-specific interactive game-based virtual reality rehabilitation system for patients with stroke: a usability test and two clinical experiments," Journal of NeuroEngineering and Rehabilitation, vol. 11, no. 1, p. 32, Mar. 2014. [Online]. Available: http://www.jneuroengrehab.com/content/11/ $1 / 32 /$ abstract

[4] J. W. Burke, M. D. J. McNeill, D. K. Charles, P. J. Morrow, J. H. Crosbie, and S. M. McDonough, "Optimising engagement for stroke rehabilitation using serious games," The Visual Computer, vol. 25, no. 12, pp. 1085-1099, Dec. 2009. [Online]. Available: http://link.springer.com/article/10.1007/s00371-009-0387-4

[5] S. N. Merry, K. Stasiak, M. Shepherd, C. Frampton, T. Fleming, and M. F. G. Lucassen, "The effectiveness of SPARX, a computerised self help intervention for adolescents seeking help for depression: randomised controlled non-inferiority trial," $B M J$, vol. 344, no. apr18 3, pp. e2598-e2598, Apr. 2012. [Online]. Available: http: //www.bmj.com/content/344/bmj.e2598

[6] V. Brezinka, "Computer games supporting cognitive behaviour therapy in children," Clinical Child Psychology and Psychiatry, p. 1359104512468288, Dec. 2012. [Online]. Available: http://ccp.sagepub. com/content/early/2012/12/20/1359104512468288

[7] A. Cooper, The Inmates Are Running the Asylum: Why High Tech Products Drive Us Crazy and How to Restore the Sanity, 2nd ed. Pearson Higher Education, 2004.

[8] P. T. A. Junior and L. V. L. Filgueiras, "User modeling with personas," in Proceedings of the 2005 Latin American Conference on Human-computer Interaction, ser. CLIHC '05. New York, NY, USA: ACM, 2005, pp. 277-282. [Online]. Available: http: //doi.acm.org/10.1145/1111360.1111388

[9] — - "A expressão da diversidade de usuários no projeto de interação com padrões e personas," in Proceedings of the VIII Brazilian Symposium on Human Factors in Computing Systems, ser. IHC '08. Porto Alegre, Brazil, Brazil: Sociedade Brasileira de Computação, 2008, pp. 1-10. [Online]. Available: http://dl.acm.org/citation.cfm?id= 1497470.1497472 
[10] C. R. M. De Carvalho, G. C. Costa, C. D. Andrade, A. S. Gomes, and C. M. B. Cysne, "Unindo IHC e negócios através do uso de personas: um estudo de caso no mercado de aplicativos móveis," in Proceedings of the 10th Brazilian Symposium on on Human Factors in Computing Systems and the 5th Latin American Conference on Human-Computer Interaction, ser. IHC+CLIHC '11. Porto Alegre, Brazil, Brazil: Brazilian Computer Society, 2011, pp. 100-104. [Online]. Available: http://dl.acm.org/citation.cfm?id=2254436.2254455

[11] A. A. Masiero, M. G. Leite, L. V. L. Filgueiras, and P. T. A. Junior, "Multidirectional knowledge extraction process for creating behaviora personas," in Proceedings of the 10th Brazilian Symposium on on Human Factors in Computing Systems and the 5th Latin American Conference on Human-Computer Interaction, ser. IHC+CLIHC '11. Porto Alegre, Brazil, Brazil: Brazilian Computer Society, 2011, pp. 91-99. [Online]. Available: http://dl.acm.org/citation.cfm?id=2254436.2254454

[12] L. Filgueiras, P. T. A. Junior, R. Sakai, Á. G. Filho, C. Torres, and I. Barbarian, "Personas como modelo de usuários de serviços de governo eletrônico," in Proceedings of the 2005 Latin American conference on Human-computer interaction, ser. CLIHC '05. New York, NY, USA: ACM, 2005, pp. 319-324. [Online]. Available: http://doi.acm.org/10.1145/1111360.1111395

[13] R. K. Stamper, K. Althans, and J. Backhouse, "Measur: Method for eliciting, analysing and specifying user requirements." in Computerized assistance during the information systems life cycle, 1988, pp. 67-115.

[14] K. Liu, Semiotics in information systems engineering. Cambridge; New York: Cambridge University Press, 2000.

[15] K. R. H. Rodrigues, L. F. Bocanegra, V. P. Gonçalves, V. G. Carvalho, and V. P. A. Neris, "Enriquecimento de personas para apoio ao design de aplicações terapêuticas para a saúde mental," in Proceedings of the 13th Brazilian Symposium on Human Factors in Computing Systems, ser. IHC '14. Porto Alegre, Brazil, Brazil: Sociedade Brasileira de Computação, 2014, pp. 51-60. [Online]. Available: http://dl.acm.org/citation.cfm?id=2738055.2738066

[16] D. S. Melo-Solarte and M. C. Baranauskas, "Resolução de problemas e colaboração a distância: modelo, artefatos e sistema," Revista Brasileira de Informática na Educação, vol. 17, no. 2, pp. 21-35, May 2009. [Online]. Available: http://www.br-ie.org/pub/index.php/ rbie/article/view/96/83

[17] L. C. de Miranda, L. S. G. Piccolo, and M. C. C. Baranauskas, "Artefatos físicos de interação com a TVDI: desafios e diretrizes para o cenário brasileiro," in Proceedings of the VIII Brazilian Symposium on Human Factors in Computing Systems, ser. IHC '08. Porto Alegre, Brazil, Brazil: Sociedade Brasileira de Computação, 2008, pp. 60-69. [Online]. Available: http://dl.acm.org/citation.cfm?id=1497470.1497478

[18] J. Pruitt and T. Adlin, The Persona Lifecycle: Keeping People in Mind Throughout Product Design, 1st ed. Amsterdam ; Boston: Morgan Kaufmann, Apr. 2006.

[19] S. Mader, S. Natkin, and G. Levieux, "How to analyse therapeutic games: The player / game / therapy model," in Entertainment Computing - ICEC 2012, ser. Lecture Notes in Computer Science, M. Herrlich, R. Malaka, and M. Masuch, Eds. Springer Berlin Heidelberg, Jan. 2012, no. 7522, pp. 193-206. [Online]. Available: http://link.springer.com/chapter/10.1007/978-3-642-33542-6_17

[20] S. Calde, K. Goodwin, and R. Reimann, "SHS orcas: The first integrated information system for long-term healthcare facility management," in Case Studies of the CHI2002, AIGA Experience Design FORUM, ser CHI '02. New York, NY, USA: ACM, 2002, pp. 2-16. [Online]. Available: http://doi.acm.org/10.1145/507752.507753
[21] R. Achterkamp, M. Cabrita, H. op den Akker, H. Hermens, and M. Vollenbroek-Hutten, "Promoting a healthy lifestyle: Towards an improved personalized feedback approach," in 2013 IEEE 15th International Conference on e-Health Networking, Applications Services (Healthcom), Oct. 2013, pp. 725-727.

[22] C. LeRouge, J. Ma, S. Sneha, and K. Tolle, "User profiles and personas in the design and development of consumer health technologies," International Journal of Medical Informatics, vol. 82, no. 11, pp. e251-268, Nov. 2013.

[23] P. Wärnestål, P. Svedberg, and J. Nygren, "Co-constructing child personas for health-promoting services with vulnerable children," in Proceedings of the SIGCHI Conference on Human Factors in Computing Systems, ser. CHI '14. New York, NY, USA: ACM, 2014, pp. 37673776. [Online]. Available: http://doi.acm.org/10.1145/2556288.2557115

[24] M. C. C. Baranauskas and R. Bonacin, "Design—indicating through signs," Design Issues, vol. 24, no. 3, pp. 30-45, Jun. 2008. [Online]. Available: http://dx.doi.org/10.1162/desi.2008.24.3.30

[25] J. Lee and K.-Y. Lai, "What's in design rationale?" Hum.-Comput. Interact., vol. 6, no. 3, pp. 251-280, Sep. 1991. [Online]. Available: http://dx.doi.org/10.1207/s15327051hci0603 \&4 3

[26] T. P. Moran, J. M. Carroll, J. Lee, and K. Lai, Eds., Design Rationale: Concepts, Techniques, and Use. Mahwah, N.J: CRC Press, Jan. 1996.

[27] A. MacLean, R. M. Young, V. M. E. Bellotti, and T. P. Moran, "Questions, options, and criteria: Elements of design space analysis," in Design Rationale: Concepts, Techniques, and Use, ser. Lea Computers, Cognition, And Work Series, T. P. Moran and J. M. Carroll, Eds. Mahwah, NJ: Lawrence Erlbaum Associates, Jan. 1996, pp. 53-105.

[28] V. P. Gonçalves, V. P. Neris, J. Ueyama, S. Seraphini, T. C. Dias, and P. R. Geraldo Filho, "Senior citizens in interaction with mobile phones: A flexible middleware approach to support the diversity," in Proceedings of the International Conference on Software Engineering Research and Practice (SERP). The Steering Committee of The World Congress in Computer Science, Computer Engineering and Applied Computing (WorldComp), 2013, p. 1. [Online]. Available: http://search.proquest.com/openview/ 3df28c8b722e916c8c8ee41f98ef9107/1?pq-origsite=gscholar

[29] C. E. Schaefer and S. E. Reid, Eds., Game Play: Therapeutic Use of Childhood Games, 2nd ed. Wiley, Jan. 2001.

[30] K. R. H. Rodrigues, V. P. Gonçalves, and V. P. A. Neris, "Tecnologias de informação e comunicação inclusivas e o envelhecer," in Coleção Envelhecimento: Saberes e Vivências, A. C. V. Campos and E. F. e. Ferreira, Eds. Ijuí: Unijuí, 2014 (In Press).

[31] J. Nielsen, Usability Engineering, 1st ed. San Diego: Morgan Kaufmann, Sep. 1993.

[32] M. J. Muller, J. H. Haslwanter, and T. Dayton, "Participatory practices in the software lifecycle," in Handbook of Human-Computer Interaction, 2nd ed., M. Helander, T. K. Landauer, and P. Prabhu, Eds. Elsevier Science Inc., 1997, pp. 255-297.

[33] M. Kolkman, "Problem articulation methodology," PhD Thesis, University of Twente, Netherlands, 1993.

[34] D. Schuler and A. Namioka, Participatory design: perspectives on systems design. Hillsdale, N.J.: L. Erlbaum Associates, 1993.

[35] Instituto Brasileiro de Geografia e Estatísticas, Um Panorama da Saúde no Brasil: Acesso e utilização dos serviços, condições de saúde e fatores de risco e proteção à saúde. IBGE Rio de Janeiro, 2008. [Online]. Available: http://biblioteca.ibge.gov.br/visualizacao/ monografias/GEBIS $\backslash \% 20$ - $\backslash \% 20 \mathrm{RJ} /$ panorama.pdf

[36] _ " "Levantamento nacional de famílias dos dependentes químicos (lenad família)," Mar. 2014. [Online]. Available: http://inpad.org.br/_ lenad-familia/ 